Article

\title{
Structures and Absolute Configurations of Diketopiperazine Alkaloids Chrysopiperazines A-C from the Gorgonian-Derived Penicillium chrysogenum Fungus
}

\author{
Wei-Feng Xu 1,2, ${ }^{\text {, Ning Mao }}{ }^{1,2,+}$, Xiao-Jia Xue ${ }^{1,2}$, Yue-Xuan Qi ${ }^{1,2}$, Mei-Yan Wei ${ }^{1,2,3}$, \\ Chang-Yun Wang ${ }^{1,2}$ and Chang-Lun Shao ${ }^{1,2, *(D)}$ \\ 1 Key Laboratory of Marine Drugs, The Ministry of Education of China, School of Medicine and Pharmacy, \\ Ocean University of China, Qingdao 266003, China; Xuweifeng_u@163.com (W.-F.X.); \\ 13012456579@163.com (N.M.); xiaoxuexiaojia@163.com (X.-J.X.); qiyuexuan9475@163.com (Y.-X.Q.); \\ mywei95@126.com (M.-Y.W.); changyun@ouc.edu.cn (C.-Y.W.) \\ 2 Laboratory for Marine Drugs and Bioproducts, Qingdao National Laboratory for Marine Science and \\ Technology, Qingdao 266200, China \\ 3 College of Food Science and Engineering, Ocean University of China, Qingdao 266003, China \\ * Correspondence: shaochanglun@163.com; Tel.: +86-532-8203-1381 \\ + These authors contributed equally to this work.
}

Received: 8 April 2019; Accepted: 24 April 2019; Published: 26 April 2019

\begin{abstract}
Three new diketopiperazine alkaloids, including two oxepine-containing diketopiperazines, chrysopiperazines A and B ( $\mathbf{1}$ and $\mathbf{2})$, and one quinazoline-containing diketopiperazine, chrysopiperazine $C(5)$, together with three known analogues $(3,4$, and 6$)$, were isolated from the gorgonian-derived Penicillium chrysogenum fungus. The relative and absolute configurations of C-3 and C-15 in $\mathbf{1}$ and 2, C-3 and C-14 in 5 were established by NOE modified Marfey's analysis and electronic circular dichroism (ECD) calculations. Particularly, the absolute configurations of C-19 in $\mathbf{1}$ and $\mathbf{3}$, which was very challenging to be identified due to the flexible conformation in a short aliphatic chain, were successfully determined by the vibrational circular dichroism (VCD) method, supplying with a reliable and optional method to define the absolute configurations. Additionally, this is the first report on oxepine-containing diketopiperazines from the genus Penicillium.
\end{abstract}

Keywords: diketopiperazine alkaloids; oxepine-containing; Penicillium chrysogenum; absolute configurations; VCD method

\section{Introduction}

Diketopiperazines are the smallest cyclic peptides, they are biosynthesised from amino acids by different organisms and are considered to be secondary functional metabolites or side products of terminal peptide cleavage [1]. Oxepine-containing diketopiperazines generally possess a tricyclic core of oxepine-pyrimidinone-diketopiperazine (OPD) derived from different amino acids [2]. Metabolites like that are rarely reported, with only 25 OPD alkaloids having been published so far. Various biological activities such as antifungal [3,4], antibacterial [2], and antiplasmodial [5], have been described. As part of our investigation on structurally novel and biologically active metabolites from marine-derived fungi [6-8], two new oxepine-containing diketopiperazines, chrysopiperazines A and $B(\mathbf{1}$ and $\mathbf{2})$; one new quinazoline alkaloid chrysopiperazine $C(5)$; and three known analogues, versicoloid B (3) [3], versicoloid A (4) [3], and versicomide C (6) [9] (Figure 1), were isolated from the gorgonian-derived Penicillium chrysogenum fungus. The relative and absolute configurations of 
C-3 and C-15 in $\mathbf{1}$ and 2, and C-3 and C-14 in $\mathbf{5}$ were elucidated by NOE modified Marfey's analysis and ECD calculations. The absolute configurations of C-19 in $\mathbf{1}$ and 3, which were very difficult to be identified, were successfully determined by VCD approach. Herein, we report the isolation and structure elucidation of the new alkaloids 1,2 , and 5 .

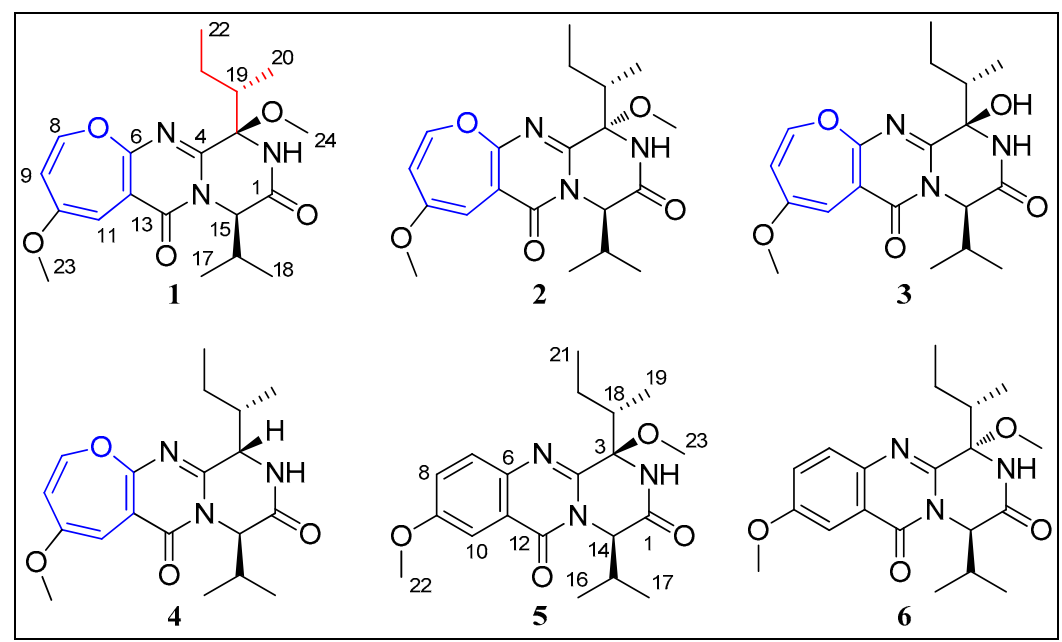

Figure 1. Chemical structures of 1-6.

\section{Results and Discussion}

Chrysopiperazine A (1) was obtained as yellow gum. Its molecular formula was determined as $\mathrm{C}_{20} \mathrm{H}_{27} \mathrm{~N}_{3} \mathrm{O}_{5}$ on the basis of the HRESIMS data at $m / z 390.2025[\mathrm{M}+\mathrm{H}]^{+}$(calcd. for $\mathrm{C}_{20} \mathrm{H}_{28} \mathrm{~N}_{3} \mathrm{O}_{5}$, 390.2023), indicating 9 degrees of unsaturation. The ${ }^{1} \mathrm{H}$ NMR spectrum (Table 1 ) showed signals of one exchangeable proton $\left[\delta_{\mathrm{H}} 7.04(\mathrm{~s})\right]$; three unsaturated protons $\left[\delta_{\mathrm{H}} 6.20(\mathrm{~d}, J=6.0 \mathrm{~Hz}), 5.80(\mathrm{~d}, J=1.4\right.$ $\mathrm{Hz})$, and $5.53(\mathrm{dd}, J=6.0,1.4 \mathrm{~Hz})]$; two methoxyl groups [ $\delta_{\mathrm{H}} 3.72(\mathrm{~s})$ and $\left.3.26(\mathrm{~s})\right]$; and four methyl groups $\left[\delta_{\mathrm{H}} 1.15(\mathrm{~d}, J=7.0 \mathrm{~Hz}), 1.04(\mathrm{t}, J=7.0 \mathrm{~Hz}), 1.00(\mathrm{~d}, J=6.9 \mathrm{~Hz})\right.$, and $\left.0.92(\mathrm{~d}, J=7.2 \mathrm{~Hz})\right]$. The ${ }^{13} \mathrm{C}$ NMR data of 1 disclosed 20 carbon signals: two amide carbonyls, four sp ${ }^{2}$ quaternary carbons, three $\mathrm{sp}^{2}$ methines, one oxygen-bearing $\mathrm{sp}^{3}$ quaternary carbon, three $\mathrm{sp}^{3}$ methines, one $\mathrm{sp}^{3}$ methylene, and six sp ${ }^{3}$ methyls. Three olefinic signals $\left(\delta_{\mathrm{H} / \mathrm{C}} 6.20 / 144.4,5.80 / 94.8\right.$, and 5.53/115.8) were typical for an oxepine ring. Detailed analysis of the 1D and 2D NMR spectra of 1 revealed that they were very similar to those of versicoloid A [3]. The key difference was the addition of a methoxyl group $\left(\delta_{\mathrm{H} / \mathrm{C}} 3.26 / 51.2\right)$ at $\mathrm{OH}-3$ in 1. This deduction was further supported by the COSY and HMBC correlations (Figure 2). Thus, the planar structure of $\mathbf{1}$ was identified as drawn in Figure 1.

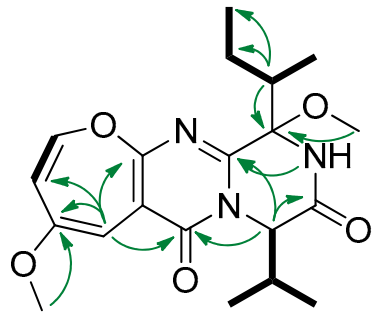

1

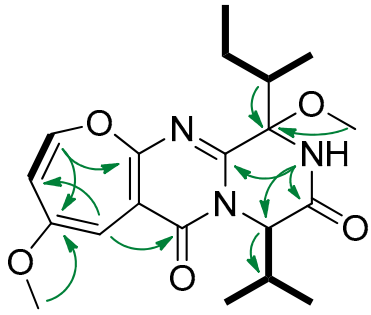

2

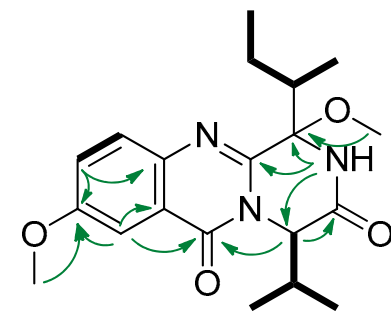

5

Figure 2. Key ${ }^{1} \mathrm{H}-{ }^{1} \mathrm{H}$ COSY (bold) and HMBC (arrows) correlations of 1, 2, and 5. 
Table 1. ${ }^{1} \mathrm{H}$ NMR and ${ }^{13} \mathrm{C}$ NMR data of $1-3^{\mathrm{a}}$.

\begin{tabular}{|c|c|c|c|c|c|c|}
\hline \multirow{2}{*}{ Position } & \multicolumn{2}{|r|}{1} & \multicolumn{2}{|r|}{2} & \multicolumn{2}{|r|}{5} \\
\hline & $\delta_{\mathrm{C}}$ & $\delta_{\mathrm{H}}(J$ in $\mathrm{Hz})$ & $\delta_{\mathrm{C}}$ & $\delta_{\mathrm{H}}(J$ in $\mathrm{Hz})$ & $\delta_{\mathrm{C}}$ & $\delta_{\mathrm{H}}(J$ in $\mathrm{Hz})$ \\
\hline 1 & 169.2 & & 166.8 & & 169.9 & \\
\hline 2 & & $7.04, \mathrm{~s}$ & & $6.10, \mathrm{~s}$ & & $6.61, \mathrm{~s}$ \\
\hline 3 & 88.1 & & 90.4 & & 88.5 & \\
\hline 4 & 149.8 & & 151.2 & & 144.6 & \\
\hline 6 & 158.3 & & 159.5 & & 140.4 & \\
\hline 7 & & & & & 129.4 & $7.66, \mathrm{~d}(9.0)$ \\
\hline 8 & 144.4 & $6.20, \mathrm{~d}(6.0)$ & 144.8 & $6.22, \mathrm{~d}(6.0)$ & 125.0 & 7.38, dd $(9.0,2.9)$ \\
\hline 9 & 115.8 & $5.53, \mathrm{dd}(6.0,1.4)$ & 115.4 & $5.52, \mathrm{dd}(6.0,1.4)$ & 159.1 & \\
\hline 10 & 157.3 & & 157.4 & & 106.2 & $7.65, \mathrm{~d}(2.9)$ \\
\hline 11 & 94.8 & $5.80, \mathrm{~d}(1.4)$ & 94.4 & $5.78, \mathrm{~d}(1.4)$ & 121.3 & \\
\hline 12 & 110.5 & & 110.6 & & 161.3 & \\
\hline \multirow{2}{*}{13} & 161.8 & & 161.3 & & & \\
\hline & & & & & 60.7 & $5.24, \mathrm{~d}(8.7)$ \\
\hline 15 & 61.0 & $5.07, \mathrm{~d}(7.8)$ & 61.2 & $5.03, \mathrm{~d}(4.1)$ & 33.4 & $2.53, \mathrm{~m}$ \\
\hline 16 & 33.3 & $2.45, \mathrm{~m}$ & 33.1 & $2.38, \mathrm{~m}$ & 19.6 & $0.95, \mathrm{~d}(6.8)$ \\
\hline 17 & 19.5 & $1.15, \mathrm{~d}(7.0)$ & 20.3 & $1.23, \mathrm{~d}(7.0)$ & 20.0 & $1.22, \mathrm{~d}(6.7)$ \\
\hline 18 & 19.7 & $1.00, \mathrm{~d}(6.9)$ & 17.8 & $0.97, \mathrm{~d}(6.9)$ & 36.2 & $2.96, \mathrm{~m}$ \\
\hline 19 & 36.4 & $2.73, \mathrm{~m}$ & 42.1 & $2.50, \mathrm{~m}$ & 10.9 & $1.07, \mathrm{~d}(7.0)$ \\
\hline 20 & 12.1 & $0.92, \mathrm{~d}(7.2)$ & 14.9 & $0.95, d(6.9)$ & 25.1 & $1.26, \mathrm{~m}, 1.00, \mathrm{~m}$ \\
\hline 21 & 24.8 & $1.11, \mathrm{~m}$ & 21.4 & $1.03, \mathrm{~m} ; 1.96, \mathrm{~m}$ & 12.4 & $0.93, \mathrm{t}(7.0)$ \\
\hline 22 & 10.6 & $1.04, \mathrm{t}(7.0)$ & 11.9 & $1.00, \mathrm{t}(6.9)$ & 55.8 & $3.96, \mathrm{~s}$ \\
\hline 23 & 55.2 & $3.72, \mathrm{~s}$ & 55.2 & $3.73, \mathrm{~s}$ & 50.9 & $3.27, \mathrm{~s}$ \\
\hline 24 & 51.2 & $3.26, \mathrm{~s}$ & 50.5 & $2.96, \mathrm{~s}$ & & \\
\hline
\end{tabular}

${ }^{\text {a }}$ Measured in $\mathrm{CDCl}_{3}, 500 \mathrm{MHz}$ for ${ }^{1} \mathrm{H}$ NMR and $125 \mathrm{MHz}$ for ${ }^{13} \mathrm{C}$ NMR.

Chrysopiperazine $\mathrm{B}(2)$ was isolated as yellow gum, with the same molecular formula, $\mathrm{C}_{20} \mathrm{H}_{27} \mathrm{~N}_{3} \mathrm{O}_{5}$, as $\mathbf{1}$ by analysis of the HRESIMS ion peak at $m / z 390.2018[\mathrm{M}+\mathrm{H}]^{+}$(calcd. for $\mathrm{C}_{20} \mathrm{H}_{28} \mathrm{~N}_{3} \mathrm{O}_{5}, 390.2023$ ). The NMR data of $\mathbf{2}$ (Table 1) were similar to those of $\mathbf{1}$, with significant differences in the chemical shift of the methoxyl group $\left(\mathrm{H}_{3}-24, \delta_{\mathrm{H}} 2.96\right.$ in 2 VS 3.26 in 1). Detailed analysis of the spectroscopic data (Figure 2) deduced the same planar structure for $\mathbf{2}$ as for $\mathbf{1}$.

Chrysopiperazine $\mathrm{C}$ (5) was obtained as colorless gum with the molecular formula of $\mathrm{C}_{20} \mathrm{H}_{27} \mathrm{~N}_{3} \mathrm{O}_{4}$ on the basis of its HRESIMS at $374.2075[\mathrm{M}+\mathrm{H}]^{+}$(calcd. for $\mathrm{C}_{20} \mathrm{H}_{28} \mathrm{~N}_{3} \mathrm{O}_{4}, 374.2074$ ). The NMR data of $\mathbf{5}$ (Table 1) were similar to those of $\mathbf{1}$, with obvious differences in the chemical shift of 1,2,4trisubstituted aromatic ring $\left[\delta_{\mathrm{C} / \mathrm{H}} \mathrm{C} / \mathrm{H}-7, \mathrm{C} / \mathrm{H}-8, \mathrm{C} / \mathrm{H}-10,129.4 / 7.66(\mathrm{~d}, J=9.0 \mathrm{~Hz}), 125.0 / 7.38(\mathrm{dd}, J=9.0\right.$, $2.9 \mathrm{~Hz}), 106.2 / 7.65(\mathrm{~d}, J=2.9 \mathrm{~Hz})$ in $5 \mathrm{VS}$ C/H-8, C/H-9, C/H-11, 144.4/6.20 (d, J = 6.0 Hz), 115.8/5.53 (dd, $J=6.0,1.4 \mathrm{~Hz}), 94.8 / 5.80(\mathrm{~d}, J=1.4 \mathrm{~Hz})$ in 1]. Detailed analysis of the spectroscopic data (Figure 2) of 5 established the planar structure as drawn in Figure 1. Chrysopiperazine A (1) could be an oxidation product of chrysopiperazine C (5) [2].

The relative configurations of $\mathrm{C}-3$ and $\mathrm{C}-15$ in $\mathbf{1}$ and 2, and $\mathrm{C}-3$ and $\mathrm{C}-14$ in 5 were assigned by the analyses of selective 1D NOE data (Figure 3). In the NOE experiment of 1 , the irradiation of $\mathrm{H}-16\left(\delta_{\mathrm{H}}\right.$ 2.45) resulted in the enhancement of $\mathrm{H}_{3}-24\left(\delta_{\mathrm{H}} 3.26\right)$, which suggested that $\mathrm{H}-16$ and $\mathrm{H}_{3}-24$ should be placed on same sides of the ring. In 2 , the irradiation of $\mathrm{H}-15\left(\delta_{\mathrm{H}} 5.03\right)$ resulted in the enhancement of 
the signal for $\mathrm{H}_{3}-24\left(\delta_{\mathrm{H}}\right.$ 2.96), which suggested that $\mathrm{H}-15$ and $\mathrm{H}_{3}-24$ should be cis-oriented. Similarly, the selective NOE experiments of 5 indicated that $\mathrm{H}-15$ and $\mathrm{H}_{3}-23$ were cis-oriented by the irradiation of $\mathrm{H}-15\left(\delta_{\mathrm{H}} 2.53\right)$, which resulted in the enhancement of the signal for $\mathrm{H}_{3}-23\left(\delta_{\mathrm{H}} 3.27\right)$.

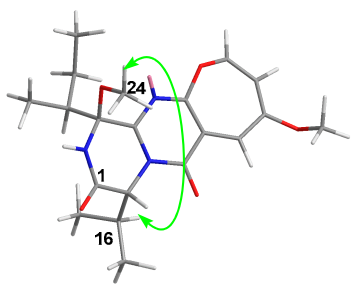

1

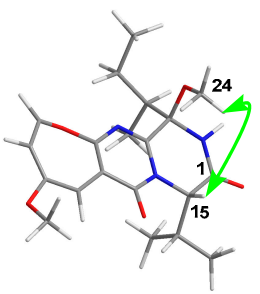

2

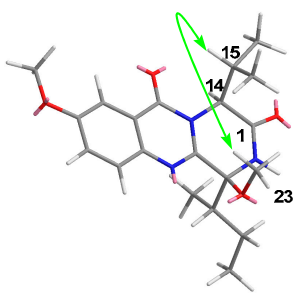

5

Figure 3. Key NOE correlations of 1, 2, and 5.

To determine the absolute configuration of the valine residue, 1 was hydrolyzed with $6.0 \mathrm{M} \mathrm{HCl}$ at $100{ }^{\circ} \mathrm{C}$ for $12 \mathrm{~h}$ and derivatized with Marfey's reagent [10], followed by comparative HPLC analysis with derivatized standard D and L-amino acids. Surprisingly, an L:D valine ratio of 1:6.7 was observed. Because the NMR spectra did not show a mixture of C-15 epimers, a series of acid hydrolysis conditions were further conducted and hydrolysis results are summarized (Supplementary Materials Figure S24). Only D valine was attained with the modest hydrolysis conditions (6 $\mathrm{M} \mathrm{HCl}$ at $80{ }^{\circ} \mathrm{C}$ for $\left.4 \mathrm{~h}\right)$. With increasing hydrolysis time and temperature $\left(6 \mathrm{M} \mathrm{HCl}\right.$ at $110{ }^{\circ} \mathrm{C}$ for $\left.36 \mathrm{~h}\right)$, both $\mathrm{L}$ and $\mathrm{D}$-valine residues were observed $(\mathrm{L} / \mathrm{D}$-valine $=1: 2.4)$. The above results revealed that the configuration of $\mathrm{C}-15$ was $R$, which originated from the D-valine. The absolute configurations of C-15 in 2 and 3, and C-14 in 5 , were also determined as $R$ by Marfey's method. Since the relative configurations of C-3 and C-15 in 1, 2, and 3, and C-3 and C-14 in 5 were confirmed, therefore, the absolute configurations of the diketopiperazine ring were determined as $3 R$ and $15 R$ in $1,3 S$ and $15 R$ in $2,3 R$ and $15 R$ in 3 , and $3 R$ and $14 R$ in 5 , respectively.

The absolute configurations of C-15 in $\mathbf{1}$ and $\mathbf{3}$ were further confirmed by comparing experimental results with that of the computed ECD (Supplementary Materials Figure S28). By comparison, the ECD spectrums of 1, 2 and 3, with positive (around $220 \mathrm{~nm}$ ) first and negative (around $250 \mathrm{~nm}$ ) second Cotton effects, indicated that the configurations at C-15 can greatly influence the ECD Cotton effects; on the opposite side, the configurations at C-3 have little influence on the ECD Cotton effects. It should be mentioned that it is very challenging to identify the configurations of the chiral centers in flexible positions. Until now, the absolute configurations of C-19 in 1, 2, and 3, and C-18 in 5 have not been assigned by the above methods. Based on the above data, two possible absolute configurations, (3R,15R,19S)-1/3 and (3R,15R,19R)-1/3, were present for $\mathbf{1}$ and 3, respectively. Firstly, the predicted ECD spectra of two possible structures $[(3 R, 15 R, 19 S)-\mathbf{1} / \mathbf{3}$ and $(3 R, 15 R, 19 R)-\mathbf{1} / \mathbf{3}]$ of $\mathbf{1}$ and 3 were calculated using the TD-DFT method at the B3LYP/6-311+G(2d,p)//B3LYP/6-31+G(d) level. The results showed that both of the predicted ECD spectra for $(3 R, 15 R, 19 S)-\mathbf{1} / \mathbf{3}$ and $(3 R, 15 R, 19 R)-\mathbf{1} / \mathbf{3}$ matched well with the measured ECD spectra of 1 and 3 (Supplementary Materials Figure S28), suggesting that it was hard to determine the absolute configurations of C-19 in the side chains of $\mathbf{1}$ and 3 by ECD method. Recently, the VCD approach has become a robust and reliable alternative for the stereochemical characterizations of natural products [11,12]. Thus, the experimental IR and VCD spectra of 1 and 3 (8.0 and $7.8 \mathrm{mg}$ ) were measured in $100 \mu \mathrm{L}$ of $\mathrm{CDCl}_{3}$ using a BioTools dual PEM ChiralIR-2X spectrophotometer. The IR and VCD frequencies of (3R,15R,19S)-1/3 and (3R,15R,19R)-1/3 were calculated at the B3LYP/DGTZVP//B3LYP/DGTZVP level in gas phase and the spectra were used to compare with the experimental IR and VCD spectra of $\mathbf{1}$ and $\mathbf{3}$. As shown in Figure 4 and Supplementary Materials Figure S32, all of the calculated IR and VCD signals of (3R,15R,19S)-1/3 had agreements with the experimental IR and VCD signals of $\mathbf{1} / \mathbf{3}$, indicating the $(3 R, 15 R, 19 S)$ configuration for 1 and 3. Based on the common biosynthetic origin, the absolute configurations of C-19 in 2 and 4 , and $\mathrm{C}-18$ in $\mathbf{5}$ and $\mathbf{6}$, were presumed to be the same as that of $\mathbf{1}$ and $\mathbf{3}$ for $S$. 

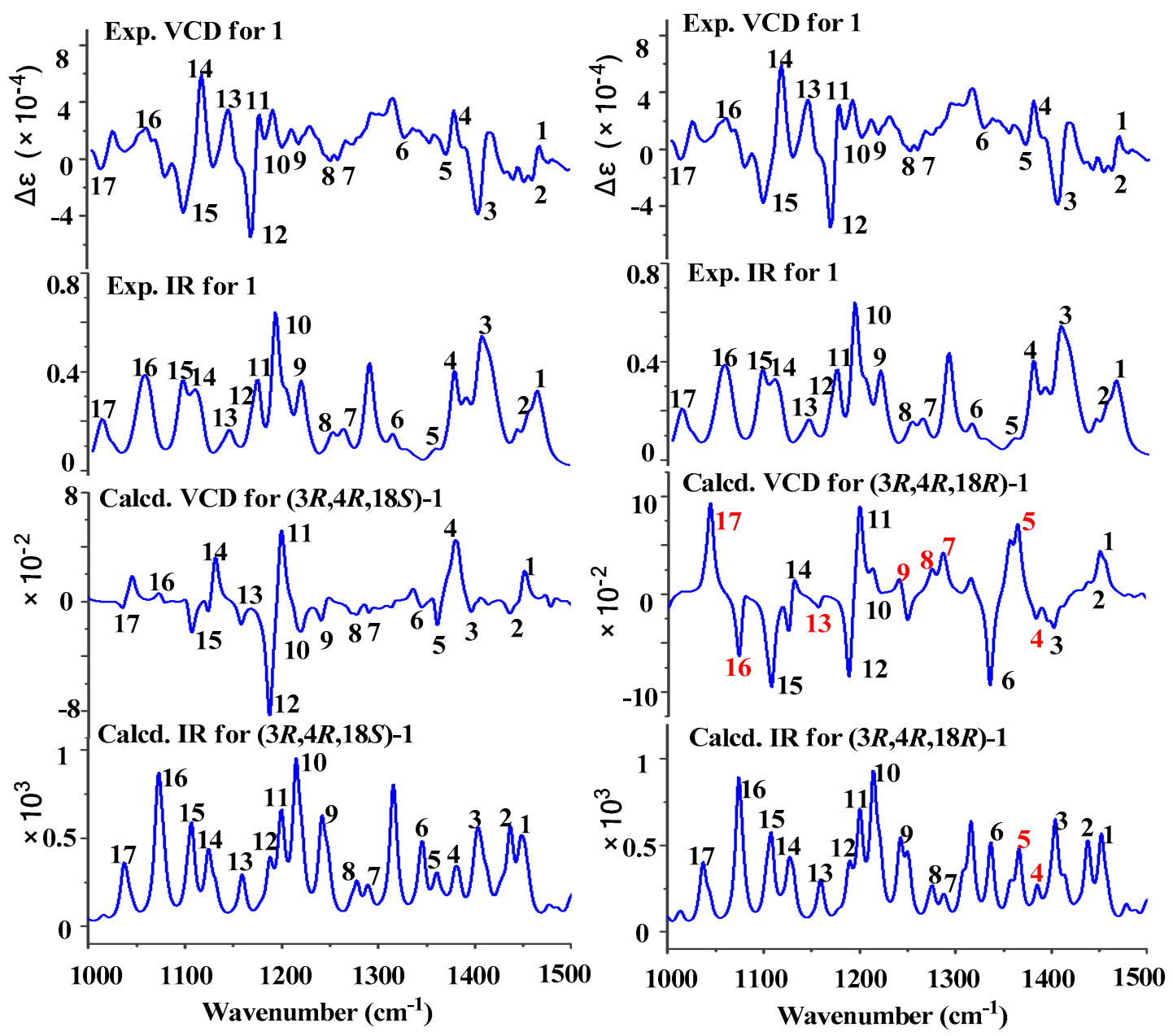

Figure 4. Experimental and calculated VCD/IR spectra of $\mathbf{1}$.

Up to now, only 25 OPD alkaloids have been reported from nature sources. They are cinereain (Botrytis cinerea [13]), oxepinamides A-G (Acremonium sp. [14], Aspergillus puniceus [15]), janoxepin (Aspergillus janus [5]), brevianamides $\mathrm{L}, \mathrm{O}$, and $\mathrm{P}$ (Aspergillus versicolor [16,17]), protuboxepins $\mathrm{A}-\mathrm{D}$, and F-G (Aspergillus sp. [18,19], Aspergillus versicolor [20]), dihydrocinereain (Aspergillus carneus [21]), varioxepine A (Paecilomyces variotii [2]), varioloids A and B (Paecilomyces variotii [4]), versicoloids A and B (Aspergillus versicolor [3]), and versicomide D (Aspergillus versicolor [9]). To the best of our knowledge, this is the first report of OPD alkaloids from the genus Penicillium. Because of the configurational flexibility of the isoleucine residue, only 5 of the 13 compounds were assigned for their absolute configurations of C-19 (Table 2). It was reported that the absolute configuration of C-19 could be determined by single-crystal X-ray difraction analysis (oxepinamide E [15] and protuboxepin C [19]) and Marfey's method (versicomide D [9]), and deduced by the biosynthetic pathway (oxepinamide F [15] and protuboxepin D [19]). However, the oily compounds were difficult to be cultured single crystals for X-ray analysis, and Marfey's method was also limited to be used due to the oxidation of C-3. In this paper, the efficient VCD method was successfully applied to elucidate the absolute configuration of $\mathrm{C}-19$ for the first time. This provides a reliable and optional method to define the absolute configurations of the analogues. 
Table 2. OPD alkaloids containing C-19 chiral carbon.

\begin{tabular}{|c|c|c|c|}
\hline Compd. & Source & $\begin{array}{l}\text { Absolute Configuration } \\
\text { of C-19 }\end{array}$ & Method \\
\hline Oxepinamide $\mathrm{A}^{14}$ & Acremonium sp. & not determined & - \\
\hline Oxepinamide $\mathrm{B}^{14}$ & Acremonium sp. & not determined & - \\
\hline Brevianamide $\mathrm{L}^{16}$ & Aspergillus versicolor & not determined & - \\
\hline Brevianamide $\mathrm{O}^{17}$ & A. versicolor & not determined & - \\
\hline Brevianamide $\mathrm{P}^{17}$ & A. versicolor & not determined & - \\
\hline Protuboxepin $\mathrm{A}^{18}$ & Aspergillus sp. & not determined & - \\
\hline Oxepinamide $\mathrm{E}^{15}$ & A. puniceus & $S$ & X-ray \\
\hline Oxepinamide $\mathrm{F}^{15}$ & A. puniceus & $S$ & biosynthetic origins \\
\hline Versicoloid $\mathrm{A}^{3}$ & A. versicolor & not determined & - \\
\hline Versicoloid B ${ }^{3}$ & A. versicolor & not determined & - \\
\hline Versicomide $\mathrm{D}^{9}$ & A. versicolor & $S$ & acid hydrolyzed \\
\hline Protuboxepin $\mathrm{C}^{19}$ & Aspergillus sp. & $S$ & X-ray \\
\hline Protuboxepin $\mathrm{D}^{19}$ & Aspergillus sp. & $S$ & biosynthetic origins \\
\hline Chrysopiperazine A & P. chrysogenum & $S$ & VCD \\
\hline Chrysopiperazine B & P. chrysogenum & $S$ & VCD \\
\hline
\end{tabular}

Compounds 1 and 3 were evaluated for the antibacterial activity against Escherichia coli, Staphylococcus aureus, Pseudomonas aeruginosa, Photobacterium halotolerans, and Enterobacter cloacae, and the antifungal activity against Canidia albicans. However, they were inactive at the concentration of $50 \mu \mathrm{M}$.

\section{Materials and Methods}

\subsection{General Experimental Procedures}

Optical rotations were measured on a JASCO P-1020 digital polarimeter ((JASCO Ltd., Tokyo, Japan) at $25^{\circ} \mathrm{C}$ with $\mathrm{MeOH}$ as solvent. UV spectra were recorded on a Beckman DU 640 spectrophotometer (Beckman Instruments Ltd., Brea, CA, USA). Circular dichroism spectra were recorded with a Jasco J-815-150S circular dichroism spectrometer (JASCO Ltd., Tokyo, Japan). Vibrational circular dichroism spectra were measured on a BioTools ChiralIR-2X spectrophotometer (BioTools, Inc., Jupiter, FL, USA). ${ }^{1} \mathrm{H},{ }^{13} \mathrm{C}$, NOE NMR, and 2D-NMR spectra were recorded at $500 \mathrm{MHz}$ for ${ }^{1} \mathrm{H}$ and $125 \mathrm{MHz}$ for ${ }^{13} \mathrm{C}$ on a JEOL JEM-ECP NMR spectrometer (JEOL Ltd., Tokyo, Japan). Chemical shifts $(\delta)$ are reported in ppm, using TMS as the internal standard, and coupling constants $(J)$ are in hertz $(\mathrm{Hz})$. High-resolution electrospray ionization mass spectrometry (HRESIMS) spectra were measured on a Micromass Q-TOF mass spectrometer (Waters Ltd., Beverly, MA, USA). High-performance liquid chromatography (HPLC) separation was performed using a Hitachi L-2000 prep-HPLC system coupled with a Hitachi L-2455 photodiode array detector (Hitachi, Tokyo, Japan). The semipreparative HPLC column used was a Kromasil C18 column (Akzo Nobel, Amsterdam, Holland, $7 \mu \mathrm{m}, 10 \times 250 \mathrm{~mm}$ ). Silica gel (100-200 and 200-300 mesh) (Qingdao Haiyang Chemical Co., Ltd., Qingdao, China), Sephadex LH-20 (Amersham Biosciences Inc., Piscataway, NJ, USA), and octadecylsilyl silica gel (45-60 $\mu \mathrm{m})$ (Merck KGaA, Darmstadt, Germany) were used for column chromatography. Thin layer chromatography (TLC) was precoated with silica gel GF 254 plates (Yantai Zi Fu Chemical Co., Ltd., Yantai, China). 


\subsection{Biological Material}

The fungal strain P. chrysogenum (CHNSCLM-0019) was isolated from a piece of fresh sample of gorgonian Dichotella gemmacea collected in the South China Sea. The fungus was identified as P. chrysogenum using its morphological traits and a molecular protocol by DNA amplification and sequencing of the ITS region. The strain was deposited in the Key Laboratory of Marine Drugs, School of Medicine and Pharmacy, Ocean University of China, Qingdao, P.R. China, with the GenBank (NCBI) access number MK696221.

\subsection{Extraction and Isolation}

The fungal strain P. chrysogenum (CHNSCLM-0019) was grown on solid media in 100 Erlenmeyer flasks $(1 \mathrm{~L})$ each containing $70 \mathrm{~g}$ of rice, $1.2 \mathrm{~g}$ of glucose, $0.36 \mathrm{~g}$ of peptone, $0.84 \mathrm{~g}$ of yeast extract, $120 \mathrm{~mL}$ of water, and $3.6 \mathrm{~g}$ of sea salt. The fungus were fermented at $28^{\circ} \mathrm{C}$ for 6 weeks before harvest.

The fermented solid medium was extracted five times with a mixture of $350 \mathrm{~mL} \mathrm{CH} \mathrm{Cl}_{2} / \mathrm{MeOH}$ (1:1) with each Erlenmeyer flask. The organic extracts were evaporated under vacuum to recovered organic solvents and then partitioned with EtOAc. The combined EtOAc solution was evaporated to dryness under a vacuum to afford the crude extract $(80.0 \mathrm{~g})$. The whole extract was subjected to vacuum-liquid chromatography (VLC) on a silica gel (200-300 mesh) column using a gradient of $\mathrm{CH}_{2} \mathrm{Cl}_{2}-\mathrm{MeOH}(100: 0$ to $0: 100, v / v)$ to yield four subfractions (Fr. A-Fr. D). Fr. B was subjected to column chromatography on silica gel (200-300 mesh) eluted with petroleum ether/EtOAc (100: 0 to 0: 100, v/v) to afford six subfractions (Fr. B1-Fr. B6). Fr. B2 was subjected to CC over reverse-phase silica gel (ODS) using step-gradient elution with $\mathrm{MeOH}-\mathrm{H}_{2} \mathrm{O}(25: 75$ to 100:0, v/v) to separate into nine subfractions (Fr. B2-1-Fr. B2-13). Fr. B2-5 was applied to Sephadex LH-20 (MeOH) and further purified by HPLC using a C18 (Kromasil $7 \mu \mathrm{m}, 10 \times 25 \mathrm{~mm})$ column at a flow rate of $2.0 \mathrm{~mL} / \mathrm{min}(60 \%$ $\left.\mathrm{MeOH} / \mathrm{H}_{2} \mathrm{O}\right)$ to yield $4\left(1.0 \mathrm{mg}, t_{\mathrm{R}}=23.5 \mathrm{~min}\right), \mathbf{2}\left(4.0 \mathrm{mg}, t_{\mathrm{R}}=31.2 \mathrm{~min}\right)$, and $\mathbf{1}\left(8.5 \mathrm{mg}, t_{\mathrm{R}}=34.0 \mathrm{~min}\right)$. Fr. B2-5 was purified by semi-preparative HPLC using $\mathrm{MeOH}-\mathrm{H}_{2} \mathrm{O}(65 \%)$ as eluent to yield $6(4.2 \mathrm{mg}$, $\left.t_{\mathrm{R}}=23.2 \mathrm{~min}\right)$. Fr. B2-6 was separated by semi-preparative HPLC $\left(\mathrm{MeOH}: \mathrm{H}_{2} \mathrm{O}=75: 25, v / v\right)$ to give compound 5 ( $\left.4.4 \mathrm{mg}, t_{\mathrm{R}}=19.3 \mathrm{~min}\right)$. Fr. B3 was applied to Sephadex LH-20 chromatography eluting with mixtures of $\mathrm{CH}_{2} \mathrm{Cl}_{2} / \mathrm{MeOH}$ (1:1) to obtain five subfractions (Fr. B3-1-Fr. B3-5). Fr. B3-2 was chromatographed on a ODS column using $\mathrm{MeOH}-\mathrm{H}_{2} \mathrm{O}(50 \%)$ and then subjected to semi-preparative $\mathrm{HPLC}\left(60 \% \mathrm{MeOH} / \mathrm{H}_{2} \mathrm{O}\right)$ to yield $3\left(8.0 \mathrm{mg}, t_{\mathrm{R}}=32.8 \mathrm{~min}\right)$.

\subsubsection{Chrysopiperazine A (1)}

Yellow gum; $[\alpha]_{\mathrm{D}}^{20}$ : -84.8 (c 0.45, MeOH); UV (MeOH) $\lambda_{\max }(\log \varepsilon): 254$ (3.72), 355 (3.58) nm; CD $(\mathrm{MeOH}) \lambda \max (\Delta \varepsilon): 220(+78.5), 253(-76.4) ;{ }^{1} \mathrm{H}$ NMR and ${ }^{13} \mathrm{C}$ NMR data, see Table 1 ; HRESIMS $\mathrm{m} / \mathrm{z}$ $358.1764\left[\mathrm{M}-\mathrm{OCH}_{3}\right]^{+}$(calcd. for $\mathrm{C}_{19} \mathrm{H}_{24} \mathrm{~N}_{3} \mathrm{O}_{4}, 358.1761$ ), $390.2025[\mathrm{M}+\mathrm{H}]^{+}$(calcd. for $\mathrm{C}_{20} \mathrm{H}_{28} \mathrm{~N}_{3} \mathrm{O}_{5}$, 390.2023).

\subsubsection{Chrysopiperazine B (2)}

Yellow gum; $[\alpha]_{\mathrm{D}}^{20}:-10.7$ (c 0.38, MeOH); UV (MeOH) $\lambda_{\max }(\log \varepsilon): 257$ (3.74), 357 (3.62) nm; CD $(\mathrm{MeOH}) \lambda \max (\Delta \varepsilon): 220(+78.5), 252(-56.8) ;{ }^{1} \mathrm{H}$ NMR and ${ }^{13} \mathrm{C}$ NMR data, see Table 1 ; HRESIMS $\mathrm{m} / \mathrm{z}$ $358.1758\left[\mathrm{M}-\mathrm{OCH}_{3}\right]^{+}$(calcd. for $\mathrm{C}_{19} \mathrm{H}_{24} \mathrm{~N}_{3} \mathrm{O}_{4}, 358.1761$ ), $390.2018[\mathrm{M}+\mathrm{H}]^{+}$(calcd. for $\mathrm{C}_{20} \mathrm{H}_{28} \mathrm{~N}_{3} \mathrm{O}_{5}$, 390.2023).

\subsubsection{Chrysopiperazine C (5)}

Colorless gum; $[\alpha]_{\mathrm{D}}^{20}:-24.3(c 0.2, \mathrm{MeOH}) ; \mathrm{UV}(\mathrm{MeOH}) \lambda_{\max }(\log \varepsilon): 225$ (4.22), 282 (3.68), 324 (3.35) nm; $\mathrm{CD}(\mathrm{MeOH}) \lambda \max (\Delta \varepsilon): 220(+27.3), 237(-78.5), 282(+7.6), 326(-9.3),{ }_{i}^{1} \mathrm{H} \mathrm{NMR}$ and ${ }^{13} \mathrm{C}$ NMR data, see Table 1; HRESIMS $m / z 342.1811\left[\mathrm{M}-\mathrm{OCH}_{3}\right]^{+}$(calcd. for $\mathrm{C}_{19} \mathrm{H}_{24} \mathrm{~N}_{3} \mathrm{O}_{3}, 342.1812$ ), $374.2075[\mathrm{M}+\mathrm{H}]^{+}$(calcd. for $\mathrm{C}_{20} \mathrm{H}_{28} \mathrm{~N}_{3} \mathrm{O}_{4}, 374.2074$ ). 


\subsection{Preparation and Analysis of Marfey's Derivatives}

Compounds $(0.2 \mathrm{mg})$ were separately hydrolyzed for $30 \mathrm{~min}$ to $36 \mathrm{~h}$ in $6.0 \mathrm{M} \mathrm{HCl}$ under different temperatures (ranging from $40{ }^{\circ} \mathrm{C}$ to $110{ }^{\circ} \mathrm{C}$ ). After cooling, the solutions were evaporated to dryness and redissolved in $\mathrm{H}_{2} \mathrm{O}(50 \mu \mathrm{L})$. The above hydrolysis solutions were added $200 \mu \mathrm{L}$ of $0.5 \%(w / v)$ FDAA (Marfey's reagent; 1-fluoro-2,4-dinitrophenyl-5-L-alanine amide) in acetone solution. After the addition of $20 \mu \mathrm{L} 1 \mathrm{M} \mathrm{NaHCO}_{3}$ solution, the mixture was incubated at $45^{\circ} \mathrm{C}$ for $40 \mathrm{~min}$. The reactions were stopped by the addition of $20 \mu \mathrm{L}$ of $2 \mathrm{M} \mathrm{HCl}$. The solvents were evaporated to dryness, and the resulting residues were dissolved in $20 \mu \mathrm{L}$ of $\mathrm{MeOH}$. Separately, L-Val and D-Val were derivatized with FDAA in the same manner as that of natural products. The standard amino acid derivatives were analyzed by HPLC (Kromasil $10 \times 250 \mathrm{~mm}, 7 \mu \mathrm{m}, 1.0 \mathrm{~mL} / \mathrm{min}$ ) with linear gradient: (A) $\mathrm{CH}_{3} \mathrm{CN}$ and (B) $\mathrm{H}_{2} \mathrm{O}$ with $0.1 \%$ trifluoroacetic acid $30-50 \%$ A (0-30 min), $50-100 \%$ A (30-35 min), $100 \%$ A (35-37 $\mathrm{min}), 100-30 \%$ A (37-40 $\mathrm{min})$, detected at $340 \mathrm{~nm}$. The retention times of the FDAA derivatives of L-Val and D-Val were 14.4 and 18.2 min, respectively.

\subsection{Bioactivity Assay}

The antibacterial activity activity of $\mathbf{1}$ and $\mathbf{3}$ against Escherichia coli, Staphylococcus aureus, Pseudomonas aeruginosa, Photobacterium halotolerans, and Enterobacter cloacae, and antifungal activity against Canidia albicans were evaluated by using 96-well microtiter plates [22], with ciprofloxacin and SeaNine 211 as positive controls.

\section{Conclusions}

Three new diketopiperazine alkaloids, chrysopiperazines A-C (1-3), were isolated from the gorgonian-derived Penicillium chrysogenum fungus and their relative and absolute configurations were comprehensively established by NOE modified Marfey's analysis, ECD and VCD calculations. This research also provides a series of combined methods to define the absolute configurations of complicated natural products.

Supplementary Materials: The following are available online at http://www.mdpi.com/1660-3397/17/5/250/s1, Figure S1-S29: 1D ( ${ }^{1} \mathrm{H}$ NMR, ${ }^{13} \mathrm{C}$ NMR, and NOE) spectra, and 2D (COSY, HSQC, and HMBC) spectra and HRESIMS of new compounds 1, 2, and 5, CD spectra of $\mathbf{2}$ and 5, Marfey's analysis of 1-3, and 5, and experimental and calculated ECD and VCD/IR of $\mathbf{1}$ and 3, Scheme S1: Reaction of the derivatization with the Marfey's reagent, Table S1-S8: The coordinate for the lowest-energy conformer in VCD calculations.

Author Contributions: W.-F.X., N.M., and X.-J.X. contributed to extraction, isolation, identification, and manuscript preparation; M.-Y.W. and C.-Y.W. contributed to NMR analysis and structure elucidation; Y.-X.Q. contributed to biological evaluation; C.-L.S. is the project leader organizing and guiding the experiments and manuscript writing.

Funding: This work was supported by the Program of National Natural Science Foundation of China (Nos. U1706210 and 41776141), the Fundamental Research Funds for the Central Universities (No. 201841004), and the Taishan Scholars Program, China.

Acknowledgments: We would like to thank Fei Cao (Hebei University) for assistance with quantum chemistry calculations and Yu-Cheng Gu (Syngenta Jealott's Hill International Centre) for his proof reading of the manuscript.

Conflicts of Interest: The authors declare no conflict of interest.

\section{References}

1. Martins, M.B.; Carvalho, I. Diketopiperazines: Biological activity and synthesis. Tetrahedron 2007, 63, 9923-9932. [CrossRef]

2. Zhang, P.; Mandi, A.; Li, X.M.; Du, F.Y.; Wang, J.N.; Li, X.; Kurtán, T.; Wang, B.G. Varioxepine A, a $3 H$-oxepine-containing alkaloid with a new oxa-cage from the marine algal-derived endophytic fungus Paecilomyces variotii. Org. Lett. 2014, 16, 4834-4837. [CrossRef]

3. Wang, J.F.; He, W.J.; Huang, X.L.; Tian, X.P.; Liao, S.R.; Yang, B.; Wang, F.Z.; Zhou, X.J.; Liu, Y.H. Antifungal new oxepine-containing alkaloids and xanthones from the deep-sea-derived fungus Aspergillus versicolor SCSIO 05879. J. Agric. Food Chem. 2016, 64, 2910-2916. [CrossRef] [PubMed] 
4. Zhang, P.; Li, X.M.; Wang, J.N.; Wang, B.G. Oxepine-containing diketopiperazine alkaloids from the algal-derived endophytic fungus Paecilomyces variotii EN-291. Helv. Chim. Acta 2015, 98, 800-804. [CrossRef]

5. Sprogøe, K.; Manniche, S.; Larsen, T.O.; Christophersen, C. Janoxepin and brevicompanine B: Antiplasmodial metabolites from the fungus Aspergillus janus. Tetrahedron 2005, 61, 8718-8721. [CrossRef]

6. Hou, X.M.; Liang, T.M.; Guo, Z.Y.; Wang, C.Y.; Shao, C.L. Discovery, absolute assignments, and total synthesis of asperversiamides A-C and their potent activity against Mycobacterium marinum. Chem. Commun. 2019, 55, 1104-1107. [CrossRef] [PubMed]

7. Wei, M.Y.; Li, D.; Shao, C.L.; Deng, D.S.; Wang, C.Y. ( \pm )-Pestalachloride D, an antibacterial racemate of chlorinated benzophenone derivative from a soft coral-derived fungus Pestalotiopsis sp. Mar. Drugs 2013, 11, 1050-1060. [CrossRef]

8. Jia, Y.L.; Wei, M.Y.; Chen, H.Y.; Guan, F.F.; Wang, C.Y.; Shao, C.L. (+)-and (-)-Pestaloxazine A, a pair of antiviral enantiomeric alkaloid dimers with a symmetric spiro [oxazinane-piperazinedione] skeleton from Pestalotiopsis sp. Org. Lett. 2015, 17, 4216-4219. [CrossRef]

9. Pan, C.Q.; Shi, Y.T.; Chen, X.G.; Chen, C.A.; Tao, X.Y.; Wu, B. New compounds from a hydrothermal vent crab-associated fungus Aspergillus versicolor XZ-4. Org. Biomol. Chem. 2017, 15, 1155-1163. [CrossRef]

10. Marfey, P. Determination of D-amino acids. II. Use of a bifunctional reagent, 1, 5-difluoro-2, 4-dinitrobenzene. Carlsberg Res. Commun. 1984, 49, 591-596. [CrossRef]

11. Zhu, A.; Yang, M.Y.; Zhang, Y.H.; Shao, C.L.; Wang, C.Y.; Hu, L.D.; Cao, F.; Zhu, H.J. Absolute configurations of 14, 15-hydroxylated prenylxanthones from a marine-derived Aspergillus sp. fungus by chiroptical methods. Sci. Rep.-UK. 2018, 8, 10621. [CrossRef] [PubMed]

12. Cao, F.; Meng, Z.H.; Mu, X.; Yue, Y.F.; Zhu, H.J. Absolute configuration of bioactive azaphilones from the marine-derived fungus Pleosporales sp. CF09-1. J. Nat. Prod. 2019, 82, 386-392. [CrossRef]

13. Cutler, H.G.; Springer, J.P.; Arrendale, R.F.; Arison, B.H.; Cole, P.D.; Roberts, R.G. Cinereain: A novel metabolite with plant growth regulating properties from Botrytis cinerea. Agric. Boil. Chem. 1988, 52, 1725-1733. [CrossRef]

14. Belofsky, G.N.; Anguera, M.; Jensen, P.R.; Fenical, J.W.; Köck, M. Oxepinamides A-C and fumiquinazolines H-I: Bioactive metabolites from a marine isolate of a fungus of the genus Acremonium. Chem. Eur. J. 2000, 6, 1355-1360. [CrossRef]

15. Lu, X.H.; Shi, Q.W.; Zheng, Z.H.; Ke, A.B.; Zhang, H.; Huo, C.H.; Ma, Y.; Ren, X.; Li, Y.Y.; Lin, J.; et al. Oxepinamides: Novel liver X receptor agonists from Aspergillus puniceus. Eur. J. Org. Chem. 2011, 2011, 802-807. [CrossRef]

16. Li, G.Y.; Yang, T.; Luo, Y.G.; Chen, X.Z.; Fang, D.M.; Zhang, G.L. Brevianamide J, a new indole alkaloid dimer from fungus Aspergillus versicolor. Org. Lett. 2009, 11, 3714-3717. [CrossRef]

17. Li, G.Y.; Li, L.M.; Yang, T.; Chen, X.Z.; Fang, D.M.; Zhang, G.L. Four new alkaloids, brevianamides O-R, from the fungus Aspergillus versicolor. Helv. Chim. Acta 2010, 93, 2075-2080. [CrossRef]

18. Lee, S.U.; Asami, Y.; Lee, D.; Jang, J.; Ahn, J.S.; Oh, H. Protuboxepins A and B and protubonines A and B from the marine-derived fungus Aspergillus sp. SF-5044. J. Nat. Prod. 2011, 74, 1284-1287. [CrossRef] [PubMed]

19. Tian, Y.Q.; Lin, S.N.; Zhou, H.; Lin, S.T.; Wang, S.Y.; Liu, Y.H. Protuboxepin C and protuboxepin D from the sponge-derived fungus Aspergillus sp. SCSIO XWS02F40. Nat. Prod. Res. 2018, 32, 2510-2515. [CrossRef]

20. Luo, X.; Chen, C.; Tao, H.; Lin, X.; Yang, B.; Zhou, X.; Liu, Y. Structurally diverse diketopiperazine alkaloids from the marine-derived fungus Aspergillus versicolor SCSIO 41016. Org. Chem. Front. 2019, 6, 736-740. [CrossRef]

21. Zhuravleva, O.I.; Afiyatullov, S.S.; Yurchenko, E.A.; Denisenko, V.A.; Kirichuk, N.N.; Dmitrenok, P.S. New metabolites from the algal associated marine-derived fungus Aspergillus carneus. Nat. Prod. Commun. 2013, 8 , 1071-1074. [CrossRef] [PubMed]

22. Appendino, G.; Gibbons, S.; Giana, A.; Pagani, A.; Grassi, G.; Stavri, M.; Smith, E.; Rahman, M.M. Antibacterial cannabinoids from Cannabis sativa: A structure-activity study. J. Nat. Prod. 2008, 71, 1427-1430. [CrossRef] [PubMed]

(C) 2019 by the authors. Licensee MDPI, Basel, Switzerland. This article is an open access article distributed under the terms and conditions of the Creative Commons Attribution (CC BY) license (http://creativecommons.org/licenses/by/4.0/). 